\title{
Should patients listen to how doctors frame messages?
}

Different phrasing can change a neutral message to an implicit recommendation

\author{
Gerd Gigerenzer director, Harding Centre for Risk Literacy and Centre for Adaptive Behaviour and \\ Cognition, Max Planck Institute for Human Development, Berlin, Germany
}

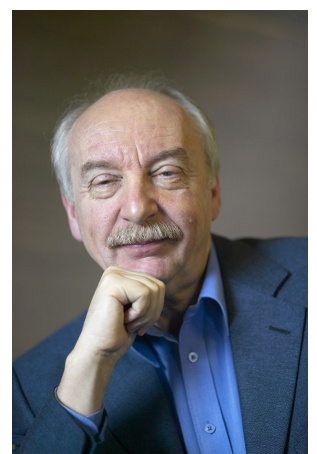

Imagine that a patient with a serious heart disease is considering potentially lethal corrective surgery and asks you what the chances are. Your response can be framed in two different ways-five years after surgery, $90 \%$ of patients are still alive (survival frame) or $10 \%$ of patients are dead (mortality frame).

Should the patient's decision depend on how you frame the message? Studies show that people are more inclined to consider surgery when the doctor uses the survival frame (albeit less so when decisions are real rather than hypothetical). ${ }^{1}$ Isn't reacting differently to the two frames-called a framing

effect-irrational? A $90 \%$ chance of survival and a $10 \%$ chance of mortality are logically equivalent. In their influential book, Nudge, Thaler and Sunstein argue that framing effects occur because "people tend to be somewhat mindless, passive decision makers" with cognitive deficiencies. ${ }^{2}$ They say that a rational patient should focus on the message, not how a doctor frames it. Framing effects are said to violate a principle called "description invariance," which is thought to be an essential condition for rational behaviour. ${ }^{3}$ In fact, framing effects are one of the justifications for the paternalist programme of the current UK government to "nudge" as opposed to educate people into changing their behaviour. ${ }^{4}$

\section{Unspoken recommendations}

All of this sounds perfectly logical. That, however, is precisely the problem. The art of risk communication entails more than just checking logical equivalence. To make an informed decision on whether to have surgery, the patient in our scenario needs to know the prospects of survival not only with surgery but also without it. Because neither frame provides information on survival without the surgery, the patient makes an intelligent inference using the frame as a cue. And the doctor provides this cue by choosing an appropriate frame. In hypothetical experiments where the alternative- - such as no surgery-led to lower survival, $80-94 \%$ of participants chose to communicate the information using the survival frame, and this frame was chosen less frequently in situations where the opposite was true. ${ }^{56}$ Thus, a doctor's choice between logically equivalent frames can communicate unspoken information, including recommendations. A survival frame communicates that the surgery is preferable to no surgery (or an alternative treatment); a mortality frame communicates the opposite message. Logically equivalent messages are not necessarily psychologically equivalent.

There are several reasons why doctors may want to avoid making an explicit recommendation while signalling what may be best for the patient, such as fear of litigation if an explicit recommendation goes wrong or a gut feeling. Doctors can signal their intuition by choosing the corresponding frame.

\section{Keeping it neutral}

It has been claimed that framing and its effects are unavoidable given that every expert must choose a frame. ${ }^{2}$ But there is another alternative. Doctors can avoid having to choose between survival and mortality framing by conveying both-five years after surgery, $90 \%$ of patients are alive and $10 \%$ are dead. Studies show that when full information is provided framing effects tend to disappear. ${ }^{7-9}$ Thus, it is possible to communicate a neutral message if desired.

One might object to doctors' use of framing on the grounds that it can mislead people into consenting to unnecessary treatment. But that is true for every form of communication, including numbers, pictures, or gestures. Rather than providing evidence for passive decision making, framing effects reflect people's social intelligence for making informed guesses about what the other party intends to communicate but does not say explicitly. These inferences may not always be correct; nonetheless, 
deciphering unspoken messages is a crucial aspect of the art of risk communication. ${ }^{10}$ It pays to speak and listen carefully instead of simply thinking logically.

Competing interests: I have read and understood BMJ policy on declaration of interests and have no relevant interests to declare.

Provenance and peer review: Commissioned; not externally peer reviewed.

Moxey A, O'Connell D, McGettigan P, Henry D. Describing treatment effects to patients. $J$ Gen Intern Med 2003;18:948-59.

2 Thaler RH, Sunstein CR. Nudge: improving decisions about health, wealth, and happiness. Yale University Press, 2008.

3 Tversky A, Kahneman D. Rational choice and the framing of decisions. J Bus 1986;59:S251-78.
4 House of Lords. Science and Technology Select Committee. 2nd Report of Session 2010-12. Behaviour Change. 2011. www.publications.parliament.uk/pa/ld201012/ldselect/ Idsctech/179/179.pdf.

5 McKenzie CR, Nelson JD. What a speaker's choice of frame reveals: reference points, frame selection, and framing effects. Psychon Bull Rev 2003;10:596-602.

6 Sher S, McKenzie CR. Information leakage from logically equivalent frames. Cognition 2006;101:467-94.

7 Kühberger A. The framing of decisions: a new look at old problems. Organ Behav Hum Decis Process 1995;62:230-40.

8 Kühberger A, Tanner C. Risky choice framing: task versions and a comparison of prospect theory and fuzzy-trace theory. J Behav Decis Making 2010;23:314-29.

9 Mandel DR. Gain-loss framing and choice: separating outcome formulations from descriptor formulations. Organ Behav Hum Decis Process 2001:85:56-76.

10 Keren G. Perspectives on framing. Psychology Press, 2011.

Cite this as: BMJ 2014;349:g7091

(c) BMJ Publishing Group Ltd 2014 